\title{
Caregiver-Child Interaction in a Rural Village in South Africa
}

\author{
Belinda K Seeff: and Melissa A Bortz \\ Department of Speech Pathology and Audiology, \\ University of the Witwatersrand
}

\begin{abstract}
The aim of this study was to describe the caregiver-child interaction in a South African rural village. A social interactional approach was adopted and a triangulation of methods was used. The interaction of nine caregiver-child dyads was observed during a semi-structured play situation, and the caregivers were interviewed concerning their beliefs about, and attitudes towards their child's communication. Interactions were rated according to an interactional profile and common themes found during the interviews, were identified. Interview results showed that although the majority of caregivers assigned importance to interacting and playing with children, their reported actions were not congruent with this. Caregivers played a dominant role during the social play interactions. Support was found for the utilisation of the social interactional approach and a triangulation of methods. Results obtained have important implications for the South African speech-language pathologist.
\end{abstract}

\section{OPSOMMING}

Die doel van hierdie navorsing was om oppasser-kind-interaksies binne 'n landelike gemeenskap van Suid-Afrika te beskryf. Nege oppasser-kind-interaksies is wargeneem tydens 'n semi-gestruktureerde spelsituasie, en onderhoude is met die oppassers gevoer, om hulle houdings en oortuigings met betrekking tot hulle kind se kommunikasie vas te stel. Die interaksies is volgens ' $n$ interaskieprofiel beskryf, en temas wat deurlopend tydens die onderhoude voorgekom het, is ge ̈̇entifiseer. Uit die onderhoude het dit geblyk dat die oppassers se handelinge nie ooreeengestem het met die meederheidsmening dat spel en interaksie met kinders belangrik is nie. Die oppassers het ' $n$ dominante rol gespeel tydens die interaksies. Die resultate het die benutting van die sosiale interaksionele benadering en 'n triangulasienavorsingsmetodiek gesteun. Die verkreë resultate hou belangrike implikasies in vir die praktiserende spraaktaalterapeut in die Suid-Afrikaanse konteks.

\section{INTRODUCTION}

"The profession of speech, language and hearing therapy is under pressure in South Africa to provide services to the majority of the population" (Mckenzie, 1992). However, a prerequisite to providing appropriate services, is an understanding of the cultural beliefs and practices of this majority in relation to speech and language issues. This is based on Taylor's (1986, p. 16) assertion that "social and cultural factors undergird all clinical activities in speech, language and audiology". At present the lack of information regarding these issues, is seen as a major obstacle to the provision of appropriate services to the diverse, multicultural South African population. Therefore, it is essential that exploratory research in this area is undertaken.

Upon recognising the relevance of social and cultural factors in the field of speech-language pathology and audiology, a pragmatic or social-interactive approach may be adopted when focusing on the area of language acquisition. This approach gained popularity in the late 1970 's, when researchers, such as Bates (1976) and Snow
(1977), challenged the conclusiveness of Chomsky's nativist theory of language acquisition. They concluded that it is not only the nature of the child, but the nature of the social interactive setting in which language is learned, which influences the pattern of language acquisition. After long ignoring the importance of the social setting for learning, attention was turned to assessing the support for language learning that children gain from their environment, as well as from those with whom they interact.

In accordance with this, numerous researchers (Bruner, 1975; Bullowa, 1979; Kretschmer \& Kretschmer, 1979; Snow \& Ferguson, 1977) have supported the notion that "competence in communicating must be learned within the course of everyday caregiving and play transactions between the child and the caregiver" (Cole \& St.Claire-Stokes, 1984, p.200). Other authors have highlighted the importance of social play interaction in the acquisition of essential language and communication skills (Bruner, 1986; Craig \& Gallagher, 1986; Reifel, 1992). As a result, most recent studies concerned with children's communicative interactions, con- 
centrate on describing interactions during social play (Guttman \& Frederiksen, 1985).

In addition to this, Duchan (1989, p.16) postulates that "if children learn most of their language in their everyday interactions with those in their environment, then it becomes expedient for speech-language pathologists to examine what occurs in these interactions." Emphasis is placed on the dyadic nature of the adultchild interaction (Garrard, 1988) and it's potential importance in the language development of the child. Therefore, the study of the nature of everyday caregiving and play interactions between caregivers and children is of vital importance in the understanding of early communication development.

At present, nearly all developmental and intervention data available is based on the assessment of "normal, white mainstream children from middle-class, two parent families" (Westby \& Erickson, 1992, p.V1). Goldberg (1977) points out that often, this Western experience is taken to be normal and even when attempts are made to adapt an approach to local experience, the premises remain Western. An example of this is The Hanen Early Language Parent Program (Manolson, 1985) which is based on traditional Western assumptions concerning various cultural issues related to child language. Van Kleeck (1992) provides a critique of the application of this program to non-mainstream cultures. She postulates that the failure often experienced, is due to non-mainstream cultural values and beliefs, that impact on interactive patterns, opposing those of the program. Therefore, this study endeavoured to establish a preliminary data base of specific non-Western cultural values and beliefs.

A further rationale for this study related to the dire shortage of speech-language pathologists and audiologists in South Africa. Aron (1991) estimated that of all the people who require speech therapy in South Africa, only $1.81 \%$ receive it from the approximately 558 working therapists. This situation mirrors the world wide lack of adequate resources and personpower needed to continue providing effective speech services on a oneto-one basis. Thus, the need arises to move away from the traditional, individualistic type of therapy setting and at the same time explore the feasibility of alternative intervention models. One such intervention model is the family-centred approach (Westby, 1990) where the parents, and specifically the mother, become ideal candidates as intervention partners. This is based on the knowledge of many Western mainstream cultures, where it is assumed that the parents, and particularly mothers, are the primary caregivers (Schieffelin \& Eisenberg, 1984; Westby, 1990). However, consideration of the South African experience, where it is common for children to spend "considerable periods of time away from one or both parents" (Reynolds, 1989, p.34), highlights the need for investigation into the applicability of this type of intervention model within the South African context.

In 1978, Penn stressed the need to "embark on the journey of acquiring knowledge of developmental and social linguistic norms within our country, as a prerequisite for accurate diagnosis and treatment" (p.242). Sixteen years later, it is clearly evident that despite the growing recognition of the impact of sociolinguistic factors on both the acquisition of, and attitudes towards communicative competence, traditional Western based assessment and therapeutic procedures continue to be implemented. As the ramifications of this concept are particularly hard felt in our multi-cultural South African population, it is essential that speech-language pathologists and audiologists begin establishing a much needed database of diverse socio-cultural beliefs and practices. In light of this, the purpose of this study was to describe the nature of caregiver-child interaction, in a rural village in the Eastern Transvaal.

\section{METHODOLOGY}

\subsection{AIMS}

The aims of this study were:

- To describe the caregivers' practices, attitudes and beliefs concerning their interaction with their children, from information gathered during interviews held with the caregivers.

- To observe, transcribe and analyse the interactions between the caregivers and their children through the medium of social play.

\subsection{RESEARCH DESIGN}

An exploratory descriptive design was utilised. This design implies that a qualitative approach was adopted. In describing the holistic, qualitative approach, Patton \& Westby (1992) assert that a description and understanding of the social environment or context is essential for an overall understanding of what is to be observed. In accordance with this, the researcher lived with the people in the village for the period of six days in which the semi-structured observations and interviews took place.

The benefits of living with the people during the performance of research, proved to be two-fold:

Familiarity with the subjects was established. By working with the people in the context of their lives, a relationship of trust between the researcher and the subjects was encouraged (Reynolds, 1989).। This was necessary in order to secure the co-operation of the subjects, which Giddens (1989) views as being an essential factor in increasing the reliability of the data to be obtained.

In addition to being able to observe the subjects in their natural environment prior to the implementation of the research, the researcher was able to sketch a general description of the village and its inhabitants.

\subsection{DESCRIPTION OF VILLAGE}

As a result of the absence of any official information pertaining to the village, a brief description of the village and its inhabitants, as seen through the eyes of the researcher, is provided.

Manzini village is one of the villages situated in the Nsikazi region of the Eastern Transvaal, located between the towns of White River and.Nelspruit. The predominant language spoken in the village'is Siswati. The village consists of mud, brick and corrugated iron houses, on small plots found scattered on the hills characteristic of the area. 
As no farm land is available to the people, they are unable to generate their own resources. Through discussion with the village dwellers, it was established that the village is seen as a labour reserve for the surrounding farms, as well as the nearest towns. Of the people who remain in the village, income is generated by activities such as selling petty goods, running shebeens and repairing cars. However, it was observed that the majority of people living in the village were unemployed.

As many of the men work varying distances away from the village, the daily population of the village is comprised largely of women, children and those adolescents who have finished or left school, and cannot find work. The daily activities of the women mainly consisted of cleaning the inside and outside of their houses, fetching water, cooking food and sitting under a tree talking to their neighbours.

It was observed that the large population of children generally played in groups of varying ages, as they wandered from house to house. In accordance with Reynold's (1989) findings during research on a squatter settlement, adults were rarely observed to be involved in the activities of the children. Also in common with Reynold's (1989) findings, were the materials used by the children during play. The main materials used included balls and cars; a variety of items found in the environment, such as stones, sticks, water, tins and bottles; as well as items that were found in their homes, such as percussion drums and spades.

\subsection{SUBJECTS}

A purposive quota sampling procedure was used when selecting subjects (Cohen \& Manion, 1991). Information presented in Table 1, shows that the age of the children range from 2.11 years to 3.9 years, with a mean age of 3.4 years. This age range was selected as the fundamentals of communicative behaviour are mostly present by this stage (Gesell, 1978). The intellectual functioning, hearing and visual acuity of each child was informally assessed by the researcher, as well as the caregiver involved, to be within normal limits.

Although it has been shown that the education of the caregiver may have an effect on "several aspects of child's health" (Yach, Richter, Cameron \& Dewet 1993, p.22), prior observation revealed the difficulty in imposing the criteria of age and education. Therefore, although no specific age range and education level were specified, the researcher attempted to limit the range of these variables as much as possible. The age of the caregivers ranged from 22-39 years, with a mean age of: 30 years. The caregivers had no previous training in speech and language or related areas.

\subsection{METHODS AND PROCEDURES}

In order to determine the nature of mother-child interaction during play, a triangulation of methods was employed ( $\mathrm{McNeill}, 1990$ ). This implies that more than one research method was used in "an attempt to strengthen the validity of empirical evidence by reliance on more than one approach" (Bulmer, 1991, p.45).

Following a pilot study, using one caregiver-child dyad, the following two research methods and procedures were adopted:

\subsubsection{Interviews}

When addressing issues relating to children of diverse cultures, Westby (1990) postulates that interviewing provides a means for understanding the environment of the child, as well as the perceptions and values of the families concerned.

Semi-structured interviews were utilised in order to describe the practices, attitudes and beliefs of the caregivers in relation to their interaction with their children. This implies that although questions were preset, the researcher was free to modify the sequencing and wording of the questions (Cohen \& Manion, 1991). This facilitated greater understanding on the part of the caregiver, and hence increased research reliability.

In accordance with the naturalistic component of qualitative research, no attempt was made to manipulate, control or eliminate situational variables (Westby, 1992). Thus, interviews took place both inside and outside the houses, depending on the preference of the caregiver involved. Both open and closed ended questions were used.

As the researcher's knowledge of Siswati was limited, a Siswati speaking researcher was used as an in-

Table 1. Description of subjects

\begin{tabular}{|c|c|c|c|c|c|}
\hline DYAD & Age of caregiver & Age of Child & Child's Gender & Language & $\begin{array}{c}\text { Education Level of } \\
\text { caregiver }\end{array}$ \\
\hline 1 & $24 \mathrm{yrs}$ & $3.4 \mathrm{yrs}$ & $\mathbf{F}$ & Siswati & Std. 3 \\
\hline 2 & 29 yrs & $2.11 \mathrm{yrs}$ & M & Siswati & Std, 7 \\
\hline 3 & 29 yrs & $3.0 \mathrm{yrs}$ & $\mathbf{F}$ & Siswati & Std. 9 \\
\hline 4 & 37 yrs & $3.0 \mathrm{yrs}$ & M & Siswati & Std. 3 \\
\hline 5 & $30 \mathrm{yrs}$ & $3.7 \mathrm{yrs}$ & M & Siswati & Std. 6 \\
\hline 6 & 32 yrs & $3.8 \mathrm{yrs}$ & $\mathbf{F}$ & Siswati & Std. 8 \\
\hline 7 & 22 yrs & $3.0 \mathrm{yrs}$ & $\mathbf{F}$ & Siswati & Std. 3 \\
\hline 8 & 32 yrs & $3.6 \mathrm{yrs}$ & $\mathrm{M}$ & Siswati & Std. 3 \\
\hline 9 & 30 yrs & 3.9 yrs & M & Siswati & Std. 2 \\
\hline
\end{tabular}


terpreter during the interviews. The questions were asked by the interpreter, and the responses given by the caregivers were immediately transcribed orthographically.

In order to fulfil the first aim of this study, specific questions were asked in an attempt to gain an understanding of the caregivers' beliefs, attitudes and practices in relation to the following issues:

- The content of interaction with the child.

- The value assigned to talking to children.

- How children acquire language abilities.

- The value assigned to children talking.

- The value assigned to playing with children.

- The quantity of play interaction between the caregivers and their children.

- The types of games and materials used during play interaction between the caregivers and their children.

McNeill (1990) points out that there is no guarantee that what people say in interviews is a true account of what they actually do. This potential weakness inherent in the interviewing method, was addressed by the utilisation of the triangulation of methods. Thus semistructured observations of the caregiver-child interactions during social play, were performed.

\subsubsection{Observations}

Semi-structured observations were employed in order to fulfil the second aim of the study of transcribing and analysing the interaction between the caregivers and their children during social play. In the context of this study, the term 'semi structured' implies that although the situation was structured in that the caregiver was requested to play with the child, the course of the caregiver-child interaction was not controlled or predetermined by the researcher.

In accounting for the possible weakness of subjectivity often associated with observation methods (Bless \& Achola, 1990), video recordings were utilised. This served to increase the objectivity and hence the reliability and validity of the study. According to Cole \& St.Claire-Stokes (1984) a video analysis procedure systematically examines specific behaviours of both the car egiver and the child as they interact. A Phillips Video Recorder (Model VKR 684/00), using 6v Panasonic batteries, powered by a portable generator, was used.

Based on the prior observation of the children at play, as well as the pilot study, an attempt was made to provide each dyad with situationally appropriate play materials. These materials included metal tins, sticks, sand, water, a toy car, a ball and bottles. However, it was noted that during the play interactions, the caregivers and their children often used other objects within their environment, such as small planks of wood, a scarf, string, cardboard boxes, and plastic ice-cream containers. This was viewed as a strength of the exploratory nature of the research design in that strictly specifying and limiting play materials to be used, would have been indicative of the researcher's bias, and hence negatively effect the reliability of the study.

The video recordings took place in a secluded area, outside the subjects' houses. This was done in order to ensure adequate lighting needed to achieve quality video recordings, as well as to prevent interruptions caused by remarks and questions by the curious onlookers.

The total interaction time of each caregiver-child dyad was approximately 20 minutes. In recognising the cultural inappropriateness associated with using a video recorder, recording equipment was set up, but actual recording only began after approximately five minutes. This time was necessary for the subjects to become familiar with the recording set-up, as well as the procedure. The recording procedure required the researcher to be present during the caregiver-child interactions. Although familiar with the subjects, the researcher was aware of Williamson, Karp, Dalphin \& Gray's (1982, p.207) assertion that it is impossible to "observe human beings without influencing their behaviour". The researcher was aware that as she was from a different culture, this may have further influenced the subjects' behaviour.

In order to maximise the representativeness of the video recorded sample, information and instructions, adapted from Cole \& St.Claire-Stokes (1984), were given to each caregiver (See Appendix A).

\subsection{PROCESSING AND ANALYSIS OF DATA}

The processing and analysis of the data obtained was dependent on the research method utilised.

\subsubsection{Interviews}

Answers to questions were translated by the interpreter into English during the interview. The data was then transcribed orthographically.

In accordance with Cohen and Manion's (1991) procedure of analysing interview data, the researcher identified common themes, as well as individual variations, in the beliefs and practices of the caregivers regarding interaction with their children.

\subsubsection{Semi-structured Observations}

Data obtained from the semi-structured observations was transcribed orthographically by two trained people whose first language was Siswati. The data was then translated into English by the interpreter.

In keeping with the social-interactional model adopted, focus was placed on analysing certain interactional components of the caregiver-child interactions. In line with the exploratory nature of this study, the profile of interactional behaviours was only drawn up after the researcher had lived with and observed the people, and obtained the video recorded data from the pilot study. Thus, the researcher was not confined to preconceived variables and the inclusion of new interactional variables was made possible (Salter Ainsworth, 1977).

\section{- Interactional Profile}

The interactional behaviours and their descriptions are presented in Appendix B. This profile was adapted from Bedrosian, Wanska, Sykes, Smith \& Dalton (1988) and Conti-Ramsden \& Dykins' (1991).

The interactional behaviours were classified into verbal and non-verbal behaviours. In addition, a break- 
down of the total number of utterances made by the caregivers and children was also calculated. It must be noted that it was possible for an 'utterance' to be analysed a number of times into different categories. Frequency counts were done and percentages calculated by the researcher.

\section{- Inter-rater Reliability}

- Thirty percent of the data was randomly selected and independently recoded as suggested by ContiRamsden \& Dykins (1991). Two raters, a qualified speech-language pathologist and a final year speechlanguage pathology student, performed this task. This suggestion, made by Conti-Ramsden \& Dykins (1991) was followed in order to reduce experimental bias and increase the reliability of the study (Silverman, 1977).

- Raters were familiarised with the required analysis scheme by means of oral instructions.

- They were required to make coded judgements relating to the verbal and non-verbal behaviours of the caregivers and children.

- Inter-rater reliability of between $75-100 \%$ was obtained utilising the following equation provided by McReynolds \& Kearns (1983, p.86):

Number of agreement $\mathrm{x} \frac{100}{1}$ Total number of agr eements and disagreements

$=\%$ agreement

\section{RESULTS AND DISCUSSION}

The results obtained from interviews and observations, and the discussion thereof, are presented below.

\subsection{INTERVIEWS}

\section{- The content of caregiver-child interaction}

The results illustrating the content of the caregiverchild interaction, as perceived by the caregivers, are presented in Figure 1 below! It, should be noted that the nature of the question allowed caregivers to respond positively to more than one category.

The content of interactions, as reported by the caregivers, consists mainly of instructions given by the caregiver, with very few questions or stories featuring in these interactions. The four caregivers, who reported that they mainly answer questions when interacting with their child, all commented that they do not interact with their child unless the child asks questions.

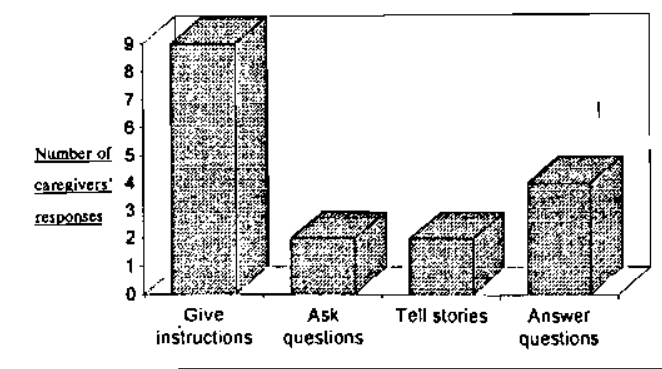

Figure 1. Content of caregiver-child interaction.

\section{- The value assigned to talking to children}

Five out of the nine caregivers thought it important to speak to their children. Three caregivers thought it unimportant to speak to their children, and one caregiver was unsure of what to answer. Bearing in mind the fact that results in Figure 1 show interactions to consist mainly of instructions, it is interesting to note that five caregivers thought it important to speak to their children besides when instructing them or sending them on errands. These caregivers suggested the following reasons for speaking to children:

" "The caregiver shows her love for the child."

- "The relationship between the caregiver and the child would be improved so that the child will no longer be scared of the caregiver."

- "The child learns new things and it helps him or her to grow. You can show them the way in life."

- "The caregiver can tell if the child is ill and if he or she can hear properly."

It can therefore be seen that the value that caregivers assigned to talking to their children related to issues of well- being, relationships and education.

\section{- How children acquire language abilities}

All nine caregivers believed that a child learns to talk through interacting with other people. However, a number of caregivers highlighted various aspects of interaction, as being crucial to language acquisition.

One caregiver identified the interaction during play with other children as a contributing factor to the child's speech development. Another caregiver highlighted the role of the child him/herself in language acquisition. She proposed that by interacting with other people and asking questions, the child learns how to talk.

Furthermore, two caregivers highlighted the mother or caregiver as playing a major role in the language acquisition of the child. They explained that the child learns to talk when he or she is in the mother's lap. The mother's role is to talk to the child during this period, before it is time for the child to go and play with other children. The caregivers stated that this occurs at approximately two years of age, when the child begins to speak. One caregiver stated that it is at this age that the mother begins to shape the child's speech.

Analysis of the responses given by the caregivers show that there are similarities between their attitudesand beliefs relating to language acquisition, and traditional Western beliefs. Among these similarities is the support for the social-interactional approach to language acquisition (Bates, 1976). The influence of the caregiver in particular, on the child's language acquisition, is also in accordance with Western researchers who have proposed that there are special properties of a mother's speech that play a significant role in language acquisition (Bernstein \& Tiegerman, 1989). In addition to this, the notion expressed by the caregivers, that at two years of age the child begins to talk, is supported by the Western language universal concept that children begin to understand and say words in approximately their second year of life (Bloom \& Lahey, 1978). 


\section{- The value assigned to children talking}

Figure 2 illustrates that only one out of the nine caregivers interviewed, thought it unimportant for a child to learn to talk. She claimed that "the child will end up talking unnecessary things." The remaining eight caregivers reacted favourably to the idea of their children talking a lot. They felt that it is through talking a lot and asking questions that a child learns about the world around him/her. Two caregivers believed that it shows intelligence when a child talks a lot, while one caregiver thought it important as "then the child will be able to cope at school and become clever."

Once again, similarities between the caregivers' values and beliefs and traditional Western values are highlighted:

- Van Kleeck (1992) asserts that talking is a behaviour highly valued in most Western cultures. This is also in accordance with Demuth's observations (1986) of the Basotho community where caregivers assigned great value to talking.

- The view expressed that talking is seen as a vehicle for further growth and learning, is related to Schiefelbusch \& Bricker's (1981) assertion that the acquisition of language allows for the development of knowledge and functions that are essential for future learning.

\section{- The value assigned to playing with children}

Figure 3 shows that eight out of nine caregivers assigned importance to playing with their children. Practical reasons, as well as those relating to relationships

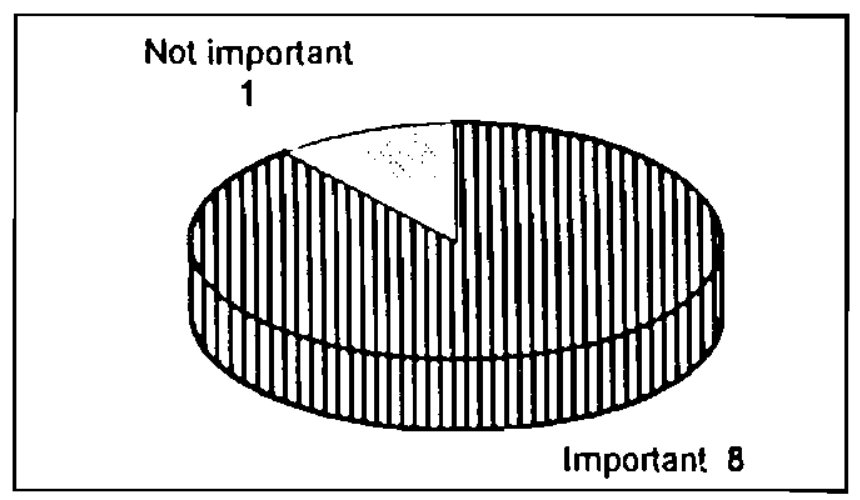

Figure 2. The value of children talking.

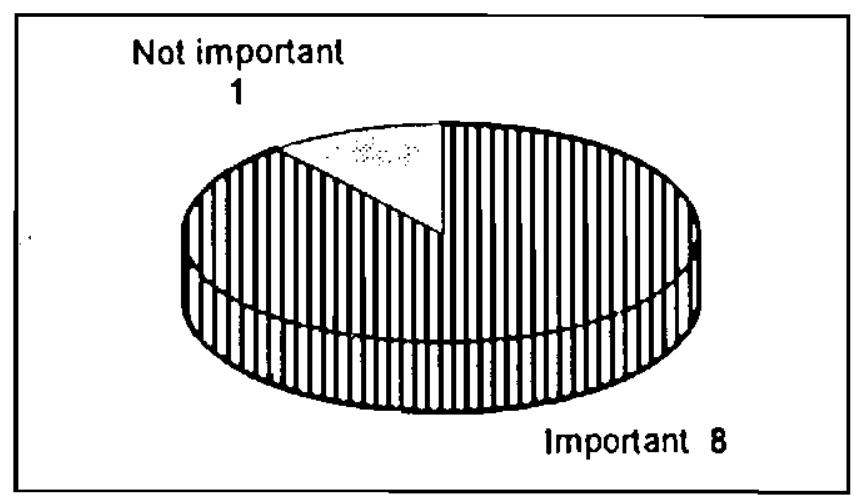

Figure 3. The value of playing with children. and cognitive development were given by the caregivers to support their beliefs. These included:

- "Playing with your child shows your love for it."

- "It keeps the child at home so that they won't wander off into other peoples' homes."

Three caregivers viewed play as an activity which "results in advances in cognitive development" (Guttman \& Frederiksen, 1985, p.165). One caregiver proposed that playing will help the child in his school work. She explained that "if a child learns how to build a house, then at school he will know how to draw it." Another caregiver stated that "it helps the child develop intelligence."

Three caregivers saw play as a means to ensure the successful performance of household chores in the future. This idea was elaborated upon by one caregiver who stated that "the child learns something for the future in the home situation - she learns to cook and do household chores." In support of this, Reynolds (1989) points out that children in non-Western societies learn by 'observation and imitation', and thus imitate adults in their play in preparation for adult roles.

\section{- The quantity of caregiver-child play interaction}

Five caregivers reported to play with their children. The amount of time spent playing ranged from less than 20 minutes per day, to less than 20 minutes per month. Only one caregiver reported to play with her child for more than 20 minutes per day. Four caregivers reported that they did not play with their children. The reasons given for not playing with their children are presented in Table 2.

It is significant to note that although eight caregivers assigned importance to playing with their children, their reported practices did not appear to be congruent with their attitudes and beliefs. The researcher hypothesises that the short and infrequent play interactions that reportedly take place, may be explained by the attitude expressed by the fourth caregiver. She believed that she would loose her respected status if she played with her child. This is directly related to Reynold's (1989) observations that she made whilst observing children in a squatter settlement near Cape Town. She observed that few adults involved themselves in the play of children, as this was regarded as being undignified.

Table 2. Reasons for not playing with children

\begin{tabular}{|c|l|}
\hline Caregiver & Reason for not playing with children \\
\hline VI & "I have too much work." \\
\hline VII & $\begin{array}{l}\text { "I don't know what to do when playing } \\
\text { with the child." }\end{array}$ \\
\hline VIII & $\begin{array}{l}\text { "I have time to play but never think that } \\
\text { I should." }\end{array}$ \\
\hline IV & $\begin{array}{l}\text { "There is time to play, but the mother will } \\
\text { loose her respected status if she plays with } \\
\text { the child - People will think that you are } \\
\text { not right in your head,." }\end{array}$ \\
\hline
\end{tabular}




\section{- Types of games played and materials used}

The caregivers stated that the games that they play with their children consist primarily of ball games, sangoma games, and a variety of domestic activities such as cooking, washing and building. It is significant to note that the domestic games played are in accordance with the view expressed by the caregivers that play is a medium through which children learn to perform household chores.

The materials that the caregivers reported to use during play, corresponded to those used by the children in Reynold's (1989) study. These materials could be classified into ready made toys, such as a skipping rope, a ball and a car; and those found in the environment and adapted for play, such as water, sand and tins.

\subsection{SEMI-STRUCTURED OBSERVATION}

\subsubsection{Verbal Behaviours}

\section{- Total number of utterances}

Results displayed in Table 3 show that the caregivers were more verbal than the children. They were responsible for at least two thirds of the total utterances spoken, with an average percentage of $80 \%$. This can be compared to the average of $20 \%$ of the total utterances made by the children.

One caregiver-child interaction served to epitomise the disproportionate number of caregiver utterances, as compared to the number of utterances said by the child. Here, $99 \%$ of the total number of utterances were made by the caregiver, whereas the child only said one utterance throughout the interaction.

\section{- Spontaneous vs response utterances}

Table 4 shows that $80 \%$ of the caregivers' utterances were spontaneous. This implies that the caregivers seldomly responded to a previous action, question, instruction or statement made by the children. When the

Table 3. Total number of subjects' utterances

\begin{tabular}{|c|c|c|c|c|}
\hline \multirow{2}{*}{} & \multicolumn{2}{|c|}{ Caregivers } & \multicolumn{2}{c|}{ Children } \\
\cline { 2 - 5 } & Range & Mean & Range & Mean \\
\hline $\begin{array}{c}\text { Utterance Total } \\
\%\end{array}$ & $66-99 \% !$ & $80 \%$ & $1-34 \%$ & $20 \%$ \\
\hline raw score & & $\mathbf{( 6 3 )}$ & & $\mathbf{( 1 6 )}$ \\
\hline
\end{tabular}

Table 4. Spontaneous versus response utterances

\begin{tabular}{|c|c|c|c|c|}
\hline \multirow{2}{*}{} & \multicolumn{2}{|c|}{ Caregivers } & \multicolumn{2}{c|}{ Children } \\
\cline { 2 - 5 } & Range & Mean & Range & Mean \\
\hline $\begin{array}{c}\text { Spontaneous } \\
\text { Utterances \% }\end{array}$ & $63-95 \%$ & $80 \%$ & $0-38 \%$ & $19 \%$ \\
\hline raw score & & $\mathbf{( 5 0 )}$ & & $\mathbf{( 4 )}$ \\
\hline $\begin{array}{c}\text { Response } \\
\text { Utterances \% }\end{array}$ & $5-37 \%$ & $20 \%$ & $62-100 \%$ & $81 \%$ \\
\hline raw score & & $\mathbf{( 1 2 )}$ & & $\mathbf{( 2 1 )}$ \\
\hline
\end{tabular}

caregivers did respond to the children, almost all of the responses were verbal $(99 \%)$.

During one caregiver-child interaction (no. 8), the caregiver responded to the child only four times out of her total of 74 utterances. During this interaction it appeared as if a combination of a lack of spontaneity and interest on the part of the child, as well as the preoccupation of the caregiver in her own activities, contributed to a general lack of responsiveness from both parties.

A general lack of spontaneity on the part of the children was noted, as only an average $19 \%$ of their total utterances were spontaneous. Thus, the majority of the utterances made by the children $(81 \%)$ were in response to an action, instruction, question or statement made by the caregivers. It is significant to note that out of the total 21 response utterances made by the children, at least half of the utterances were in reply to questions asked by the caregivers.

\section{- Topic maintenance and shift}

A general interpretation of the mean percentages of topic maintenance and topic shift on the part of the caregivers, shows an expected proportion of topic shifts as compared to topic maintenance. However, closer inspection of the range percentages associated with individual caregivers, reveals that a disproportionate amount of topic shifts occurred during one interaction. Here the caregiver used $58 \%$ of her utterances to shift topics and only $42 \%$ to maintain them.

On the whole, the caregivers shifted topics almost three times more than the children. This is in contradiction to Conti-Ramsden \& Friel-Patti's (1991) findings that normal, Western, middle-class children shifted the topics approximately three times more than their mothers did in a naturalistic play setting. In addition to this, Conti-Ramsden \& Friel-Patti (1991) assert that by introducing fewer topics than their children, mothers adjust their conversation style to match their child's, and allow the child to influence the flow of information exchanged in the conversation. As this did not occur in the course of any of the interactions observed, a lack of adjustment on the part of the caregivers, was demonstrated.

\section{- Function of utterances:}

- Instructions:

Table 6 indicates that on average, nearly half of the caregivers' utterances functioned as instructions. These results support the impression gained from the inter-

Table 5. Topic maintenance and topic shift

\begin{tabular}{|c|c|c|c|c|}
\hline \multirow{2}{*}{} & \multicolumn{2}{|c|}{ Caregivers } & \multicolumn{2}{c|}{ Children } \\
\cline { 2 - 5 } & Range & Mean & Range & Mean \\
\hline $\begin{array}{c}\text { Topic } \\
\text { maintenance \% }\end{array}$ & $42-83 \%$ & $65 \%$ & $79-100 \%$ & $89 \%$ \\
\hline raw score & & $\mathbf{( 3 9 )}$ & & $(\mathbf{1 5 )}$ \\
Topic shift \% & $17-58 \%$ & $35 \%$ & $0-21 \%$ & $11 \%$ \\
raw score & & $(\mathbf{2 3 )}$ & & $(\mathbf{2 )}$ \\
\hline
\end{tabular}


views where the caregivers indicated that the majority of their interactions with their children take the form of instructions. They also relate to Harkness's findings (1977) regarding the speech of mothers and children in the Kokwet community in Western Kenya. She found that mothers or caregivers relied on instructions for communication. Furthermore, Van Kleeck (1992) cites non-Western, rural Black communities in America who believe that it is the adult's role to issue directives and the child's role to obey them.

The general lack of assertiveness on the part of the children was illustrated as only an average of $11 \%$ of their utterances served as instructions.

\section{- Statements:}

On average, just over one third of the caregivers' utterances were statements, whereas almost half of the children's utterances were statements. This is in agreement with Harkness's findings that "children's communication is more often in the form of statements" (Harkness, 1977, p.313).

\section{- Questions:}

Results in Table 6 show that the relative proportion of questions asked by the caregivers was approximately half that of the children. Snow (1977) points out that questions serve the purpose of language elicitation in the process of facilitating language acquisition. Therefore, the relatively small number of questions asked by the caregivers becomes significant in terms of the role that these caregivers play in the language acquisition of their children.

In addition to this, $54 \%$ of the total number of questions asked by the caregivers, were not answered. It was noted during a number of interactions that the caregivers asked numerous questions without allowing any time for the child to respond, before producing the next utterance. This fact, together with the subjective observation by the researcher, leads to the conclusion that the majority of questions asked by the caregivers were probably used rhetorically.

It is interesting to note that $44 \%$ of the total number of questions asked by the children served the purpose of asking for clarification. Extreme examples of this were found in two caregiver-child interactions (no.6 \& no.8) where all the questions asked by the children were requests for clarification.

Table 6. Function of subjects' utterances

\begin{tabular}{|c|c|c|c|c|}
\hline \multirow{2}{*}{} & \multicolumn{2}{|c|}{ Caregivers } & \multicolumn{2}{c|}{ Children } \\
\cline { 2 - 5 } & Range & Mean & Range & Mean \\
\hline Instructions $\%$ & $27-73 \%$ & $44 \%$ & $0-36 \%$ & $11 \%$ \\
\hline raw score & & $(26)$ & & $(2)$ \\
\hline Statements \% & $6-55 \%$ & $37 \%$ & $0-88 \%$ & $48 \%$ \\
\hline raw score & & $(23)$ & & $(10)$ \\
\hline Questions \% & $2-34 \%$ & $19 \%$ & $9-100 \%$ & $34 \%$ \\
\hline raw score & & $(12)$ & & $(4)$ \\
\hline
\end{tabular}

\subsubsection{Non-Verbal Behaviours}

Results in Table 7 reveal almost no non-verbal responses from the caregivers. Only one caregiver responded once non-verbally to an action performed by her child. In contrast to this are the number of nonverbal responses on the part of the children. The majority of the children's responses were non-verbal and related to instructions given by the caregivers.

\subsection{GENERAL DISCUSSION}

The results obtained from the interviews and observations serve to support the social-interactional approach to language acquisition. It is evident that the interactions between caregivers and their children in the Manzini village facilitate the acquisition of communicative competence that is appropriate to the specific social and cultural communication context (Schiefelbusch \& Pickar, 1984). As Taylor \& Payne (1994) point out, cultural styles of verbal interaction do not impede language development, but may manifest in varying patterns of verbal expression. This has particular relevance in the South African context where a multitude of different cultures provide diverse interactional environments which in turn result in varying communicative behaviours. Thus, the need to investigate these interactional environments to determine the nature of communication expected, is highlighted.

The fact that results obtained from the performance of the two research methods employed were congruent with one another, serves to highlight the strength inherent in triangulation. Thus, the reliability of the study was increased and the researcher was able to gain greater insight into the phenomena under study (Bless \& Achola, 1990). This was illustrated when the caregivers' belief that through play "the child learns household chores for the future", was supported by the observation that most of the activities that took place during the caregiver-child interactions consisted of performing household chores. In line with this, the researcher is of the opinion that by observing and imitat-

Table 7. Non-verbal Responses

\begin{tabular}{|c|c|c|c|c|}
\hline \multirow{2}{*}{} & \multicolumn{2}{|c|}{ Caregivers } & \multicolumn{2}{c|}{ Children } \\
\cline { 2 - 5 } & Range & Mean & Range & Mean \\
\hline $\begin{array}{c}\text { Response to } \\
\text { question } \%\end{array}$ & $0 \%$ & $0 \%$ & $0-7 \%$ & $2 \%$ \\
\hline raw score & & $(0)$ & & $(.3)$ \\
\hline $\begin{array}{c}\text { Response to } \\
\text { instruction } \%\end{array}$ & $0 \%$ & $0 \%$ & $8-83 \%$ & $37 \%$ \\
\hline raw score & & $(0)$ & & $(\mathbf{7})$ \\
\hline $\begin{array}{c}\text { Response to } \\
\text { action } \%\end{array}$ & $0-13 \%$ & $1 \%$ & $0-6 \%$ & $\therefore \%$ \\
\hline raw score & & $(.1)$ & & $(.1)$ \\
\hline $\begin{array}{c}\text { Response to } \\
\text { statement } \%\end{array}$ & $0 \%$ & $0 \%$ & $0-7 \%$ & $1.8 \%$ \\
\hline raw score & & $(0)$ & & $(.3)$ \\
\hline
\end{tabular}


ing perceived adult roles during play, the children learn what they need to know in order to become "competent members of their society" (Skinner, 1989, p.181).

Finally, it is interesting to note that a difference occurred between the caregiver's interactions with female children as compared to male children. Upon analysing the interactions, it became evident that an interaction between a caregiver and a male child tended towards a parallel play situation, whereby the caregiver focused on her own activities and encouraged the male child to perform male orientated tasks, such as building a house or garage. More interaction took place between a caregiver and a female child as they focused on a common activity such as washing or cooking. Based on these findings, the researcher agrees with Rogoff's (1982) assertion that through everyday activities and social interactions, culturally shared meanings pertaining to gender are constructed and internalised.

\section{SUMMARY}

In this study, the nature of caregiver-child interaction in the rural village of Manzini has been described using semi-structured observation and interviewing methods. The following phenomena were found:

\subsection{INTERVIEWS}

- The majority of the caregivers thought it important for their children to talk, which they learn to do through interacting with people in their environment.

- Although playing with children was generally viewed as being important, short and infrequent play interactions take place between some of the caregivers and their children.

- The content of interaction between the caregivers and their children consists mainly of instructions given by the caregivers.

- The type of games which the caregivers play with their children, are mainly centred around domestic activities.

- Play materials consist primarily of objects found in the environment.

\subsection{SEMI-STRUCTURED OBSERVATIONS}

- The caregivers appeared to interact more with the female children than with the male children.

- A dominant role was played by the caregivers during the play interactions with their children. This was demonstrated in the following ways:

They mainly instructed the children and often asked questions without allowing time for the child to reply.

They responded minimally to actions, questions, instructions or statements made by the children.

They shifted topics often and were responsible for the majority of utterances spoken.

- The children generally took on a submissive and obedient role as was illustrated in the following ways: They made few utterances.

They tended to maintain the topics introduced by the caregivers.

Their main interactional behaviour consisted of non- verbal responses to instructions given by the caregivers.

\section{CONCLUSIONS AND IMPLICATIONS}

The clinical implications of this study are highlighted by the current cultural integration taking place within South Africa. As a result, the Western urban clinician is often faced with the task of diagnosing patients from non-Western cultures. Therefore, it is essential that speech-language pathologists and audiologists do not fall into the trap of adopting the attitude that "what is 'normal' in our culture is 'right', and that cultures that are 'different' are likely to be 'wrong' or inferior" (Tulkin 1977 , p.569). Although ideas of improving the current models of assessment have been entertained over the past few years (Taylor, Payne, Kay \& Anderson, 1987), this study provides concrete evidence to highlight the urgency of researching and developing culturally valid and sensitive assessment tools.

The views and corresponding actions of the Manzini caregivers have particular relevance when considering the possibility of utilising these caregivers as intervention partners in the therapeutic process. Although it is not possible to categorically oppose the utilisation of these caregivers as intervention partners in the traditional Western milieu, the researcher cautions that the values held by the caregivers living in the Manzini village are not entirely congruent with those held by Western urban speech-language pathologists. Accordingly, it should not be assumed that if these caregivers were to be shown a different way of interacting with their children, they would respond positively to changing their present communicative practices.

Furthermore, the ethical implications of Western urban clinicians inviting themselves into a rural village, and introducing communication behaviours that are "good and right... and in the interest of progress" (Goldberg, 1977, p.592) need to be highlighted. Although acknowledging the good intentions of the Western urban clinicians, Goldberg (1977, p.593) points out that "the greatest harm is often done by those who think that they are doing good". By imposing the values of Western cultures on this rural community, the clinicians would encourage the genocide of the community's communicative practices (Crago, 1992), and hence their cultural attitudes, meanings and values that underlie these behaviours.

The above notwithstanding, it is crucial that the large rural population within our country, is not ignored. Rather, culturally sensitive intervention should take place in the rural context, whereby the urban clinician must be acutely aware of his/her own cultural bias which may affect the type of intervention he/she hopes to provide. Communicative beliefs and practices should be exchanged between the urban clinician and the rural caregivers. By doing this, the present reciprocal ignorance, which "frequently translates into prejudice and apathy" (Adler, 1979, p.203) would be overcome. In addition, the caregivers would be able to make informed decisions concerning their beliefs and practices.

Furthermore, whilst acknowledging the obstacles that cross-cultural communicative differences present for the speech-language pathologist, in the pursuit of appropriate assessment and intervention procedures, it 
is crucial that language universals are not overlooked. It is the knowledge and application of these universals, which may provide a key to the formulation and implementation of appropriate assessment and intervention programmes.

As the sun shines brightly on a new South Africa (Archbishop Desmond Tutu, 19 April 1994), we as speech-language pathologists are faced with the challenge of providing effective services to the majority of the South African population. As the present study has clearly demonstrated, this challenge can only be met if we continue on the long but rewarding journey to acquiring knowledge of attitudes, beliefs and practices of all cultural groups within our country.

\section{REFERENCES}

Adler,S. (1979) . Poverty Children and Their Language. Implications for Teaching and Treating. Sydney. Grune and Stratton.

Aron.M.L. (1991). Perspectives. South African Journal of Communication Disorders. Vol 38. 3-11.

Bates,E. (1976). Language and Context: The Acquisition of Pragmatics. New York. Academic Press.

Bedrosian,J.L., Wanska,S.K., Sykes,K.M., Smith,A.J., \& Dalton,B.M. (1988). Conversational turn-taking violations in mother-child interactions. Journal of Speech and Hearing Research. Vol 31, 81-86.

Bernstein,D.K. \& Tiegerman,E. (1989). Language and Communication Disorders in Children. (2nd ed). Columbus OH. Charles E Merrill.

Bless,C. \& Achola,P. (1990). Fundamentals of Social research Methods: An African Perspective. Lusaka Government Printer.

Bloom,L \& Lahey,M. (1978). Language Development and Language Disorders. New York: John Wiley and Sons.

Bruner,J.S. (1975). The Ontogenesis of Speech Acts. Journal of Child Language. 2. 1-21.

Bullowa,M. (1979). Before Speech. London. Cambridge University Press.

Bulmer,M. (1991). Introduction: Problems, Theories and Methods in Sociology - How do they inter-relate? In B.Bozzoli : Study Package: Social/Industrial Sociology III: Planning and executing an research project. University of the Witwatersrand.

Cohen,L. \& Manion,L. (1991). Research Methods in Education. (3rd ed). London. Routledge Press.

Cole,E.B. \& St.Claire-Stokes,J. (1984). Caregiver-child Interactive Behaviours: A Videotape Analysis Procedure. Volta Review.

Conti-Ramsden,G. \& Dykins,J. (1991). Mother-child interactions with language-impaired children and their siblings. British Journal of Disorders of Communication. Vol 26. 337-354.

Conti-Ramsden,G. \& Friel-Patti,S. (1991). Mother-child dialogues: A comparison of normal and language impaired children. Journal of Communication Disorders. Vol 17. 1936.

Crago,M.B. (1992). "Ethnography and Language Socialisation: A Cross Cultural Perspective. Topics in Language Disorders. 12(3). 28-39. Aspen Publisher Inc.

Craig,H.K. \& Gallagher,T.M. (1986). Interactive Play - The frequency of related verbal responses. Journal of Speech and Hearing Research. Vol 29. 375-383.

Demuth,K. (1986). Prompting Routines in the Language Socialisation of Basotho Children. In B.Schieffelin \& E.Ochs (eds.) Language Socialisation Across Cultures. Cambridge University Press.

Duchan,J.F. (1989). Evaluating Adults Talk to Children: Assessing Adult Attunement. Seminars in Speech and Language. Vol 10. 1.

Garrard,K.R. (1988). A mother's language to her twins: One child Downs Syndrome and one child with normal development. Journal of Childhood Communication Disorders. Vol 12, 1.
Gesell,A. (1978). The First Five Years of Life. A Guide to the Study of the Preschool Child. London. Methuen and Co.

Giddens,A. (1989). Working with Sociology: Methods of Research. In A.Giddens : Sociology. London. Policy Press.

Goldberg,S. (1977). Ethics, politics and multicultural research. In P.H.Liederman, S.R. Tulkin \& A.Rosenfeld (eds.). Culture and Infancy: Variations in the Human Experience. New York. Academic Press.

Guttman,M. \& Frederiksen,C.H. (1985). Preschool Children's Narratives: Linking Story Comprehension, Production and Play Discourse. In L.Galda \& A.D. Pellegrini (eds.)(1985). Play, Language and Stories: The Development of Children's Literature Behaviour. USA. Ablex Publishing Corporation.

Harkness,S. (1977). Aspects of Social Environment and First Language Acquisition in Rural Africa. In C.Snow \& C.A.Ferguson (eds.). Talking to Children: Language Input and Acquisition. London. Cambridge University Press.

Kretschmer,R.R. \& Kretschmer,L.W. (1979). Language Development and Intervention with the Hearing Impaired. Baltimore. University Park.

Manolson,A. (1985). It Takes Two to Talk: A Hanen Early Language Parent Guide Book. (2nd revision). Toronto. Hanen Early Language Resource Centre.

Mckenzie,J.A. (1992). The Provision of Speech, Language and Hearing Services in a Rural District of South Africa. South African Journal of Communication Disorders. Vol 39. 5061.

McNeill,P. (1990) :Research Methods. 2nd ed. Suffolk London. Richard Clay Ltd.

McReynolds,L.R. \& Kearns,K.P. (1983). Single Subject Experimental Designs in Communicative Disorders. Baltimore. University Park Press.

Patton,M. \& Westby,C. (1992). Ethnography and Research: A Qualitative View. Topics in Language Disorders. 12(3). 114.

Penn,C. (1978). Speech Pathology and Audiology in South Africa - Past, Present and Future Perspectives. In L.Lanham \& K.Prinsloo: Current Issues and directions in Research and Inquiry. Cape Town. Oxford University Press.

Reynolds,P. (1989). Childhood in Crossroads: Cognition and Society in South Africa. Claremont. David Phillip Publisher Pty. Ltd.

Reifel,S. (1992). Play and Language in Early Childhood Introduction. Play and Culture. Vol 5. 2. 103-106.

Rogoff, B. (1982). Integrating Context and Cognitive Development. In M.E.Lamb \& A.L.Brown (eds.). Advances in Developmental Psychology. Vol 2. New York. Hillsdale. Lea.

Salter Ainsworth,M.D. (1977). Infant Development and Mother-infant Interaction among Uganda and American Families, In D.H.Liederman, S.R.Tulkin \& A.Rosenfeld : Culture and Infancy: Variations in the Human Experience. New York. Academic Press.

Schiefelbusch,R. \& Pickar,J. (1984). The Acquisition of Communicative Competence. Baltimore. University|Park Press.

Schiefelbusch,R.L. \& Bricker,D. (eds.)(1981). Early Language Acquisition and Intervention. Baltimore. University Park Press.

Schieffelin,B.B. \& Eisenberg,A.R. (1984). Cultural Variation in Children's Conversation. In R.Schiefelbusch \& J.Pickar. The Acquisition of Communicative Competence. Baltimore. University Park Press.

Silverman,F.H. (1977). Research Procedures in Speech Pathology and Audiology. New Jersey. Prentice-Hall.

Skinner,D. (1989). The Socialisation of Gender Identity: Observations from Nepal. In J.Valsiner (ed.). Child Development in Cultural Context. Toronto. Hogrefe and Huber Publishers.

Snow,C. (1977).Mother's Speech Research: From Input to Interaction. In C.Snow \&

C.A.Ferguson (eds.). Talhing to Children: Languáge Input and Acquisition. London. Cambridge University Press.

Snow,C. and Ferguson,C.A. (eds.)(1977). Talking to Children Language Input and Acquisition. London. Cambridge University Press.

Taylor,O.L. (ed.)(1986). Nature of Communication Disorders in Culturally and Linguistically. Diverse Populations. San Diego. College Hill Press. 
Taylor, O.L., Payne,K,T., Kay,T. \& Anderson,N.B. (1987). Distinguishing Between Communication Disorders and Communication Differences. Seminars in Speech and Language. Vol 8,4

Taylor, O. L. \& Payne, K.T. (1994). Language and communication differences. in G.H. Shames, E. H. Wiig \& W.A. Secord (eds.). Human communication disorders: An introduction (4th ed.). p. 136-173. New York: Macmillan Publishing Company.

Tulkin,S.R. (1977). Dimensions of Multicultural Research in Infancy and Early Childhood. In D.H.Liederman, S.R.Tulkin \& A.Rosenfeld (eds.). Culture and Infancy. Variations in the Human Experience. New York. Academic Press Inc.

Tutu,D. (1994) : TV1 News. Jhb. SABC.

Van Kleeck,A. (1992). Future Trends in Language Intervention: Addressing Cultural Bias in Service Delivery. South African Journal of Communication Disorders. Vol 39.

Westby,C.E. (1990). Ethnographic Interviewing: Asking the right questions to the right people in the right ways. Journal of Childhood Communication Disorders. Vol 13(1). 101-113.

Westby,C. \& Erickson,J. (1992). Prologue. Topics in Language Disorders. 12(3), v-vii.
Williamson, J.B., Karp,D.A., Dalphin, J.R., \& Gray,P.S. (1982) : The Research Craft: An introduction to social research methods. Boston. Little, Brown and Co.

Yach,D., Richter,L.Cameron,N. \& Dewet,T. (1993). Maternal education and child health: Emerging evidence from birth to ten. Paper presented at Birth-Ten Seminar on methods and findings of the first years. Witwatersrand Medical School. RSA.

Address correspondence to Ms B. Seeff, Department of Speech Pathology and Audiology, University of the Witwatersrand, P O Wits, 2050, Johannesburg, South Africa.

\section{ACKNOWLEDGMENTS}

The authors would like to thank Ms M Schneider, Senior Clinical Tutor, University of the Witwatersrand, for her valuable assistance in conceptualising and formulating this study.

\section{APPENDIX A}

\section{Information and instructions given to caregivers}

- Each caregiver was told that the researcher's aim was to observe how she and the child played together. The interpreter used a direct translation of the word 'play', that is 'dlala'. The interpretation of this was left up to the caregiver.

- It was further explained to each caregiver, that the researcher's intention was not to assess whether the caregiver's interaction with her child was right or wrong, and therefore their interaction should be as natural as possible.

- Each caregiver was informed that the researcher would not interact with her during the recording.

\section{APPENDIX B}

\begin{tabular}{|l|l|l|}
\hline Behaviour'Type & Description & \\
\hline VERBAL & \begin{tabular}{l} 
Utterance \\
\cline { 2 - 3 }
\end{tabular} & $\begin{array}{l}\text { A verbal expression consisting of a word, phrase or sentence. This } \\
\text { does not include utterances expressed while singing. }\end{array}$ \\
\cline { 2 - 3 } & - - Respontaneous & $\begin{array}{l}\text { An utterance not related to the previous action, statement, instruc- } \\
\text { tion or question of the interaction partner. }\end{array}$ \\
\cline { 2 - 3 } & - Topic maintenance & $\begin{array}{l}\text { An utterance related to the previous action, statement, instruction } \\
\text { or question of the interaction partner. }\end{array}$ \\
\cline { 2 - 3 } & - Instruction & An utterance requiring an action from the listener. \\
\cline { 2 - 3 } & - Question & $\begin{array}{l}\text { A request for införmation, opinion, permission, conformation or } \\
\text { clarification. }\end{array}$ \\
\cline { 2 - 3 } & - Statement/Comment & $\begin{array}{l}\text { An utterance which contains information about a topic or an ongo- } \\
\text { ing action. }\end{array}$ \\
\hline NON-VERBAL & Response & $\begin{array}{l}\text { A non-verbal reaction related to the previous action, statement, in- } \\
\text { struction or question of the interaction partner. }\end{array}$ \\
\hline
\end{tabular}

Adapted from Bedrosian, Wanska, Sykes, Smith \& Dalton (1988) and Conti-Ramsden \& Dykins (1991). 